rev.relac.int.estrateg.segur.11(2):215-238,2016

\title{
EMPRESARIOS INDUSTRIALES CHILENOS COMO ACTORES NO GUBERNAMENTALES INTERNOS Y SU PARTICIPACIÓN EN LAS INICIATIVAS DE INTEGRACIÓN LATINOAMERICANA DURANTE EL GOBIERNO DE EDUARDO FREI MONTALVA, 1964-1970*
}

\author{
Javier Eduardo Recabarren Silva**
}

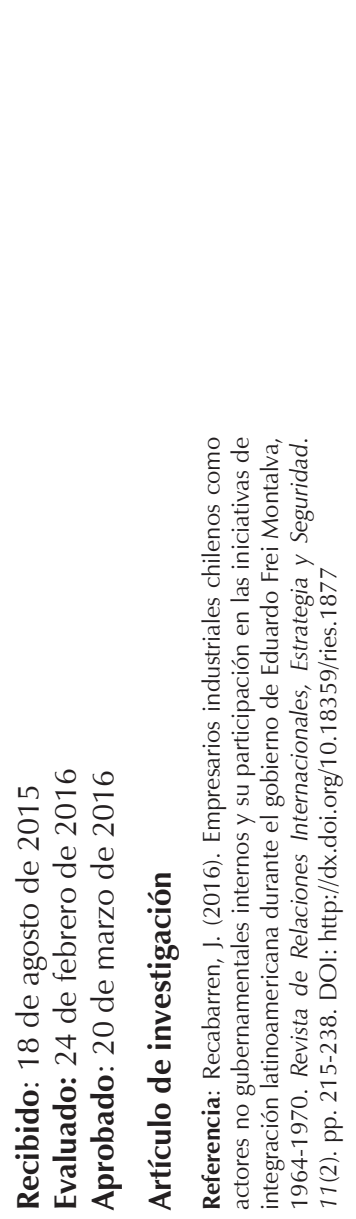

\section{RESUMEN}

El artículo analiza, en el marco de los trabajos de política exterior de Chile y los estudios de Análisis de Política Exterior, la participación y el papel que cumplieron tres importantes entidades empresariales chilenas -la Confederación de la Producción y del Comercio (CPC), la Sociedad de Fomento Fabril (Sofofa) y la Asociación de Industriales Metalúrgicos (Asimet)-, en las iniciativas del gobierno chileno de Eduardo Frei Montalva para dinamizar y profundizar el proceso de integración latinoamericana entre los años 1964 y 1970. Afirmamos que los actores empresariales escogidos apoyaron los esquemas de integración, así como las medidas del gobierno en ese proceso, de manera más intensa que en años anteriores, lo que permitió fortalecer la posición chilena para liderar cambios en la integración regional. Para tal efecto se realizó una exhaustiva recopilación

\footnotetext{
Proyecto de Investigación del Centro de Estudios de Relaciones Internacionales, Facultad de Gobierno, Universidad del Desarrollo. Investigador Asociado del Centro de Estudios de Relaciones Internacionales (CERI), Facultad de Gobierno, Universidad del Desarrollo. Magíster en Estudios Sociales y Políticos Latinoamericanos, Universidad Alberto Hurtado, Chile. Correo electrónico: javierrecabarren@udd.cl
} 
de fuentes primarias de la época y se utilizaron las variables de los estudios de Análisis de Política Exterior, para examinar la importancia de trabajar a los actores no gubernamentales internos en relación con la política exterior de un país.

Palabras clave: actores internos no gubernamentales, análisis de política exterior, Integración Latinoamericana, Pacto Andino.

\title{
CHILEAN ENTREPRENEURS INDUSTRIALS AS INTERNAL NONGOVERNMENTAL ACTORS AND THEIR PARTICIPATION IN THE LATIN AMERICA INTEGRATION INITIATIVES DURING THE EDUARDO FREI MONTALVA GOVERNMENT, 1964-1970
}

\begin{abstract}
Using the context of Chile's foreign policy and the framework of Foreign Policy Analysis studies, this article analyzes the participation and the role of three important business-sector entities in Chile -the Confederation of Production and Commerce (CPC), the Federation of Chilean Industry (Sofofa), and the Metallurgical and Metalmechanic Industries Association (Asimet). We examine the role of the three actors in Chilean government initiatives under Eduardo Frei Montalva that aimed at stimulating and consolidating Chile's integration process with the rest of Latin America between 1964 and 1970.We argue that the business-sector actors chosen here supported integration schemes, as well as government measures in the integration process, in a more intense manner than previous years, allowing for the strengthening of Chile's position to spearhead changes in regional integration. To support our argument, we compiled an exhaustive amount of primary sources from the period and used variables in Foreign Policy Analysis studies to evaluate the significance of the workings of domestic non-governmental actors in shaping the country's foreign policy.
\end{abstract}

Key words: Nongovernmental actors; Foreign Policy Analysis; Latin American integration; Andean Pact.

\section{EMPRESÁRIOS INDUSTRIAIS CHILENOS COMO PERSONAGENS NÃO GOVERNAMENTAIS INTERNOS E SUA PARTICIPAÇÃO NAS INICIATIVAS DE INTEGRAÇÃO LATINO-AMERICANA DURANTE O GOVERNO DE EDUARDO FREI MONTALVA, 1946-1970}

\section{RESUMO}

O artigo analisa, no quadro dos trabalhos da política externa do Chile e os estudos de Análise da Política de Exterior, a participação e o papel que levará a cabo três 
importantes entidades empresariais chilenas - a Confederação da Produção e do Comércio (CPC), a Sociedade para o Desenvolvimento Industrial (Sofofa) e a Associação das Indústrias Metalúrgicas (Asimet)-, nas iniciativas do governo chileno de Eduardo Frei Montalva para impulsar e aprofundar o processo de integração da América Latina entre os anos 1964 e 1970. Afirmamos que os personagens empresariais escolhidos apoiaram os esquemas de integração, assim como as medidas do governo nesse processo, de forma mais intensa que nos anos anteriores, o que permitiu fortalecer a posição chilena para liderar mudanças na integração regional. Para tal efeito se realizou uma exaustiva sínteses das fontes primárias da época e se utilizaram as variáveis dos estudos de Análise da Política Exterior, para examinar a importância de trabalhar aos personagens não governamentais internos em relação à política externa de um país.

Palavras-chave: Personagens internos não governamentais; Análise da Política Exterior; Integração da América Latina; Pacto Andino.

\section{Introducción}

Hoy día es posible observar en América Latina diversos esquemas de integración que, con distintos objetivos, se superponen unos con otros. Así encontramos algunas fórmulas amplias, tales como la Comunidad de Estados Latinoamericanos y Caribeños (CELAC) y la Unión de Naciones Suramericanas (Unasur), junto a otros procesos subregionales como son la Comunidad Andina (CAN), el Mercado Común del Sur (Mercosur), la Alianza Bolivariana de los Pueblos de Nuestra América (ALBA) y la Alianza del Pacífico.

En este panorama de diversas formulas de integración, el Estado chileno solo participa como miembro pleno de este último esquema creado en el año 2011 -sin contar la CELAC ni Unasur, que por sus objetivos no conllevan importantes compromisos nacionales-. La membrecía a este nuevo proceso ha sido, sin lugar a dudas, una "novedad" positiva para los gobiernos, la prensa y diversos actores chilenos, ya que desde el año 1976, cuando Chile se retiró del Pacto Andino, no se era miembro pleno de ningún esquema de integración económico existente.

Sin embargo, pocas veces se recuerda que Chile, durante la década de 1960, participó de manera activa en la integración económica que estaba desarrollándose en América Latina, tanto en la Asociación Latinoamericana de Libre Comercio (ALALC) como más tarde en el Acuerdo de Cartagena, en 1969. En esos esquemas, el Estado chileno fue un protagonista durante la segunda mitad de la década de 
1960 (Lagos, 1972), donde incluso ese interés por participar de manera activa traspasó las fronteras de la sola participación gubernamental. $\mathrm{Y}$ es que junto al protagonismo que tuvo el gobierno chileno, liderado por el presidente Eduardo Frei Montalva, los actores no gubernamentales internos, como los partidos políticos y grupos empresariales, también cumplieron un papel destacado desde sus diversos espacios e intereses, conscientes que debían tener un papel en estos nuevos procesos regionales (Atria, Cusack, Chellew, 1974; Wilhelmy, 1982a).

El presente trabajo tiene como principal objetivo analizar, en el marco de los trabajos que han estudiado la participación de actores no gubernamentales internos en la política exterior chilena en los procesos de integración latinoamericana, el papel que cumplieron tres importantes grupos empresariales chilenos -la Confederación de la Producción y del Comercio (CPC), la Sociedad de Fomento Fabril, (Sofofa) y la Asociación de Industriales Metalúrgicos (Asimet)-, en las iniciativas del gobierno chileno de Eduardo Frei Montalva para dinamizar y profundizar el proceso de integración latinoamericana durante su mandato entre los años 1964 y 1970.

Afirmamos que estas entidades empresariales, que en años anteriores ya se habían mostrado favorables a los procesos de integración regional, durante este período manifestaron un apoyo más intenso que ayudó a respaldar las decisiones gubernamentales en dichos esquemas, fortaleciendo la posición chilena para liderar transformaciones durante la segunda mitad de la década de 1960. Y esto sucedió así, porque ambos actores estaban interesados en que la participación nacional en el proceso de integración mejorase el desarrollo económico del país. Asimismo, esta visión común les permitió tener un punto de encuentro en un contexto en que las relaciones entre empresarios y gobierno habían comenzado siendo lejanas durante los primeros años.

Para efectos de este trabajo, entenderemos la política exterior como una actividad o programa que, elaborado y ejecutado dentro de un Estado por el gobierno de turno, se orienta a lograr determinadas metas y resolver asuntos relacionados con el plano internacional, por lo que sus decisiones afectan a entidades extranjeras que están fuera de la jurisdicción nacional (Van Klaveren, 1984). Al ser entonces un "plan" del gobierno de turno dirigido hacia el exterior, tiene la característica de verse afectada en el tiempo por variables tanto del plano internacional como doméstico, y por tanto de experimentar diversos cambios entre gobiernos $\mathrm{O}$ en un mismo período gubernamental (Hermann, 1990; Wilhelmy, 1988). 
Estudio de los actores no gubernamentales internos: El caso de los empresarios industriales chilenos

Los trabajos sobre política exterior chilena relacionados a los procesos de integración regional en las décadas de 1960 y 1970, le han otorgado un énfasis a las influencias que provienen desde el ámbito externo y sobre todo a la centralidad del papel que ha tenido el Estado, como un actor unitario en materia internacional (Medina, 2002; Wilhelmy, 1982a, Fermandois, 1985). La razón principal radicaría en las características legales y políticas del sistema político chileno, en que la política exterior es concebida como un área de ejecución y diseño del poder Ejecutivo (Wilhelmy, 1982b). Por lo que los trabajos que han abordado a los actores no gubernamentales internos en la política exterior chilena en los procesos de integración, son escasos (Atria \& Cusack, Chellew, 1974; Godoy, 1965; Wilhelmy, 1982a).

Ahora bien, como sostienen muchos estudios de Análisis de Política Exterior, incorporar factores domésticos de un país en los análisis de política exterior, permite tener una comprensión más completa de las decisiones y posiciones de un Estado en materia internacional, así como de las distintas variables que afectan el comportamiento de los diversos actores involucrados en esta (Doeser, 2011; Hermann, 1990; Hudson, 2007; Katzenstein, 1978; Neack, Hey \& Haney, 1995; Wilhelmy, 1987). Asimismo, como bien analizó
Robert Putnam (1988) en su trabajo Diplomacy and domestic politics: the logic of two-level games, los gobiernos se ven enfrentados constantemente a un juego de doble nivel, donde, por una parte, deben tener en cuenta las presiones internacionales a la hora de tomar posiciones y actuar en política internacional, pero al mismo tiempo si no logran tener la debida "resonancia" y acuerdos a nivel nacional, no podrá llevar a cabo los cambios esperados (Putnam, p. 430).

Por tanto para efectos de este trabajo, queremos destacar de entre los diversos factores domésticos que pueden afectar la política exterior, la importancia de estudiar a los actores no gubernamentales internos, como los partidos políticos y grupos empresariales, por ser ellos, en palabras de Charles Hermann (1990), una de las fuentes más importantes de cambio en política exterior. De esta manera, al examinar y comprender las posiciones e incidencias de estos actores en relación con los asuntos internacionales, se puede analizar mejor el comportamiento de la política exterior de un determinado país (Hudson, 2007, p. 128).

Para el caso específico del proceso de integración latinoamericana iniciado a principios de 1960, como logró dar cuenta el funcionario del Banco Interamericano de Desarrollo, Horacio Godoy, en su temprano estudio Actitudes frente a la integración, los actores no gubernamentales 
internos no tuvieron una actitud pasiva, e incluso a medida que se iba desarrollando y profundizando el proceso de integración, se vieron cada vez más involucrados por lo intereses que estaban en juego. Por lo que con el avance del proceso de integración, dirá Godoy, estos actores fueron reorientando sus intereses $y$ motivaciones originales (Godoy, 1965, p. 143).

Por su parte, el académico peruano Enrique Bernales también analizó la importancia de este tipo de estudios durante su participación en el seminario internacional sobre las Variables Políticas del Pacto Andino, organizado entre el Instituto de Ciencia Política de la Universidad Católica y el Centro Interuniversitario de Desarrollo Andino (CINDA) en el año 1973, y que contó con la participación del expresidente Frei Montalva. Para Bernales, la importancia de trabajar esta temática es que los procesos de integración tienen la característica de no ser esquemas estáticos en el tiempo, sino que pueden mutar como consecuencia de varios factores, entre estos, las distintas posiciones que pueden ir adoptando en el tiempo los actores internos de cada país sobre la base de sus propias convicciones ideológico-valorativas del proceso. Por lo que en determinados momentos, al actuar a favor o en contra de las políticas integracionistas del actor gubernamental, pueden llegar a afectar sus propuestas y acuerdos con otros países, lo que conlleva a que los distintos países muestren diferentes grados de consenso y fortaleza interna en sus posiciones e iniciativas (Bernales, 1974, pp. 83-84).

Creemos, por tanto, que estudiar a los tres grupos empresariales chilenos más importantes en ese entonces en relación con el proceso de integración latinoamericana y con las iniciativas del gobierno chileno en esta, permite dar cuenta que los actores no gubernamentales internos chilenos no solo participaron con fuerza en el proceso de integración, sino que también ayuda a analizar mejor los grados de apoyo interno que tuvo el gobierno de Eduardo Frei Montalva para liderar una posición reformista en los esquemas de integración entre los años 1964 y 1970.

\section{Dimensión económica e internacio- nal del gobierno de Frei: críticas y propuestas a la marcha del proceso regional}

Eduardo Frei Montalva, líder del Partido Demócrata Cristiano, se convirtió en presidente de Chile en noviembre de 1964 con un histórico $56,08 \%$ de los votos. Al poco tiempo de establecerse en el poder, puso en práctica aquellos principios y orientaciones que su partido había venido defendiendo desde hacía años en materia de integración regional (Valdés, 1967). Esto le permitió comenzar a establecer un liderazgo en el proceso de integración por medio de 
una serie de iniciativas, que al mismo tiempo afectaron a los actores no gubernamentales internos chilenos y al proceso de integración en su totalidad.

Para entender mejor lo que sucedió, deben considerarse tres dimensiones en el análisis: a) el estancamiento que se había producido en la marcha de la integración hacía el año 1964; b) la posición económica e internacional con la cual asumió el nuevo gobierno; c) y el estilo político del nuevo mandatario.

Respecto a la primera dimensión, para el año 1964 los distintos países que pertenecían a la ALALC estaban asumiendo posiciones divergentes. El telón de fondo de estas eran las distintas dimensiones de sus mercados internos, la potencialidad de sus economías y las diversas ideologías de sus respectivos gobiernos, traduciéndose en estrategias y proyectos de integración disímiles, que estaban afectando los objetivos del proceso (Magariño, 2005).

La posición chilena al respecto, venía expresando desde el año 1963 su molestia ante tal situación. La crisis del proceso regional para el gobierno chileno radicaba en las dificultades para incorporar nuevos productos en las listas nacionales, en los obstáculos para conformar la primera lista común en 1964, la falta de coordinación y planificación de políticas de desarrollo agropecuario e industrial, así como la poca diversificación del comercio, que se había mantenido en productos tradicionales (Daza, 1964, p. 16). Por último, la iniciativa chileno-brasileña del año 1963 de realizar una reunión de ministros de RR.EE., para otorgarle un apoyo político al proceso, no se concretó.

Es importante subrayar, que el trasfondo de esa percepción gubernamental chilena se sostenía en haber sido uno de los países con más alto déficit acumulado en su balanza comercial respecto a los demás países de la zona entre los años 1961 y 1964, así como un cierto nacionalismo abierto hacia el continente latinoamericano, donde se consideraba que el desarrollo nacional se alcanzaba junto a los demás países de la región (Magariños, 2005, p. 507). Esta crítica liderada por Chile era también ampliamente compartida por los países medianos, como Colombia, Uruguay y Ecuador, por lo que fue patente, hacia finales de 1964, que en el proceso de integración latinoamericana estaban enfrentándose dos posiciones que difícilmente iban a lograr armonizarse.

La segunda dimensión de análisis, esto es, la posición económica e internacional con la cual asumió el nuevo gobierno, será una que no solo intentará responder a esa situación de crisis por medio de una postura reformista a nivel discursivo y programático.

Al llegar al Palacio de la Moneda un gobierno de partido único, que no contemplaba compartir el poder con 
otra colectividad política, los nuevos roles de poder fueron ocupados por demócrata cristianos, y por tanto, será la ideología del partido la que definirá, en gran medida, el programa de gobierno y las políticas aplicadas. En otras palabras, la ideología democratacristiana, que desde la década de 1950 era abiertamente prointegración, influyó y orientó los principales temas de política exterior con "[...] un estilo de acción de corte reformista, caracterizado por un activismo en busca de sustanciales modificaciones en la posición internacional de Chile [...]" (Wilhelmy, 1982, p. 34). Por su parte, la editorial de un importante diario chileno, El Mercurio, expresó en diciembre de 1964, que la etapa retórica de la integración regional iba a modificarse tras la llegada del nuevo presidente: "las ideas básicas que conforman el estilo y pensamiento del presidente Frei y de sus colaboradores se ha visto, desde hace tiempo, en la necesidad de concebir a Chile como una entidad nacional cuyo destino se cumplirá en la medida en que se integre en una constelación de pueblos hermanos en el idioma, en la cultura, en el pasado y en la común necesidad" (El Mercurio, 1964, 11 de diciembre).

Por consiguiente, el programa de gobierno estuvo inspirado por esos temas que habían sido pilares y transversales en el partido, buscándose realizar una "revolución en libertad", es decir, reformas estructurales en distintas áreas del país dentro de un marco legal. Entre las transformaciones sociales y políticas que se querían alcanzar, estaba realizar una reforma agraria que dejara atrás el viejo sistema de latifundio, reformas de promoción social y reformas a la Constitución. Y para esto se necesitaba acelerar y triplicar la tasa de crecimiento per cápita, bajar los índices de inflación casi a cero en un período de cuatro a cinco años y redistribuir el ingreso (French-Davis, 1973, pp. 22-23).

Por consiguiente, era fundamental mejorar el sector externo de la economía, donde la política exterior era un instrumento clave, como se manifestó en el programa de gobierno de Frei: "Todo lo que Chile debe hacer en su vida interna lo relaciona, inevitablemente, con el gran mundo exterior. Somos parte del mundo, del Hemisferio Occidental y de la América Latina [...] Todo lo que podamos hacer adentro está hoy condicionado a lo que ocurre afuera" (Política y Espíritu, 1964, p. 19).

De esta manera, la estrategia de desarrollodel nuevogobiernoapuntaba, sobre la base de una concepción independiente, a mantener relaciones diplomáticas y económicas con todo el mundo mientras ayudara a los intereses del país. Y entre las mayores prioridades, se encontraba dinamizar la integración latinoamericana, pues de esta dependía la promoción industrial, la exportación de esos productos y la expansión del mercado interno (Fruhling, 1983, 231). 
Por lo anterior es que en el primer discurso realizado por el canciller Valdés ante el Congreso Nacional en enero de 1965, la integración latinoamericana era un imperativo del nuevo gobierno, al que se le pretendía abordar con "decidida voluntad" por ser esta fundamental para el crecimiento, el desarrollo y porque lograría poner el nombre de América Latina en el mundo (Valdés, 1970, p. 27). En esta lógica, también afirmó que el nuevo gobierno no estaba "satisfecho" con lo alcanzado hasta entonces en materia de integración, por lo que se defenderá la necesidad de profundizar la marcha del proceso, tanto en sus instrumentos políticos como económicos, así como hacerlo más inclusivo, incorporando a los sindicatos, universidades y demás actores que no habían tenido protagonismo (1970, pp. 28-29).

Por último, no puede dejar de analizarse la relevancia que tuvo en la nueva política exterior el perfil y estilo internacional del nuevo mandatario, quien bajo la tipología de Manfred Wilhelmy, tuvo un estilo de liderazgo "ideológico" e "impulsor" en relación con la política exterior de su gobierno. Es decir, en materia internacional Frei siempre exhibió "[...] una preocupación especial y personal por el desarrollo de nuevas iniciativas" (Wilhelmy, 1982, p. 33). Es interesante decir a este respecto, que más allá de la influencia que tuvo la ideología del partido sobre las orientaciones generales de la política exterior, la ventaja que tuvo Frei para tener una gran independencia en materia internacional y a su vez utilizarlo cuando lo requirió -a diferencia de lo que aconteció en política interna-, fue que era un líder importante dentro de su partido (Wilhelmy, 1976a, p. 30).

También se puede añadir, que los atributos de un liderazgo ideológico y propulsor no solo fueron beneficiados por la línea independiente que pudo desarrollar respecto a la directiva de su partido, sino también por las características de su propia personalidad y experiencia de vida. Por su educación, intereses y vivencias, fue una persona que desde muy temprano se cautivó por conocer la realidad internacional, convirtiéndose, al momento de ser elegido, en el mandatario más interesado y versado sobre política internacional que hasta ese entonces haya pasado por La Moneda, y con mayores y mejores vínculos internacionales (Fermandois, 2004, p. 297). Como afirmara Fermandois, "si Alessandri (presidente durante los años 19591964) probablemente se sentía incómodo en el mundo internacional, Frei resplandecía y aun se refugiaba en él" (2004, p. 308).

Por consiguiente, estos tres factores expuestos son clave a la hora de comprender el comportamiento de la política exterior chilena hacia el proceso de integración latinoamericana entre los años 1964 y 1970. En este contexto es posible entender también las primeras iniciativas llevadas a cabo 
por Frei para, de manera autónoma, inspirar a los demás países a avanzar en la profundización de la integración, tanto a nivel interno como externo.

Respecto al nivel interno, en noviembre de 1964 Frei mandó al Congreso un proyecto de modificación de la Constitución donde, entre otras cosas, incluía la autorización para delegar algunos poderes del Estado chileno a entidades supranacionales que estuviesen dedicadas a la integración y el desarrollo. Esta iniciativa tuvo la particularidad de que fue una acción realizada, no sobre la base de que otros países lo estuviesen realizando, sino que fue una apuesta unilateral (Wilhelmy, 1976a, p. 51).

A nivel externo, la iniciativa de Frei se manifestó cuando envió una carta a cuatro importantes economistas latinoamericanos -Felipe Herrera, Raúl Prebisch, Carlos Sanz de Santamaría y a Antonio Mayobre ${ }^{3}$-, expresándoles la situación de la integración, la insatisfacción sobre su marcha y las reformas urgentes para promoverla y cumplir con la meta final del Tratado de Montevideo. La respuesta que entregaron los "cuatro", como se les llamó, tuvo una amplia difusión mediática, tanto en los países de la ALALC (Magariños, 2005, p. 559) como en Europa y EE.
UU. Esto se evidenció en el reportaje que realizó el semanario The Economist en mayo de 1965, donde de una manera bastante peculiar catalogó a Frei como el "clarinetista" que llama a la unidad latinoamericana, y al grupo de los cuatro, como la pequeña banda que siempre había estado dedicada a unir económicamente a la región y que por fin había adquirido el "lanzallamas" para realizarlo -refiriéndose a Frei- (The Economist, 1965, p. 506).

Lo que en último término se esperaba de las inquietudes planteadas por el presidente chileno, y luego la respuesta que manifestaron "los cuatro" en documento de alrededor de 30 páginas, era darle un nuevo empuje al tema de la integración y que se comenzara a discutir no solo a nivel técnico sino también político.

Al momento de enviar la carta a los cuatro economistas, Frei también se preocupó de mandársela a los demás mandatarios latinoamericanos. Sin embargo, no provocó el compromiso para tomar acciones más decisorias al respecto. Esta falta de respuesta es un elemento clave al momento de querer comprender las nuevas iniciativas que Frei, junto a su canciller, llevaron a cabo para acelerar el proceso regional durante los años siguientes.

Felipe Herrera era en ese entonces presidente del BID, Raúl Prebich, secretario general de la Unctad, Carlos Sanz de Santamaría, presidente del Comité Interamericano de la Alianza para el Progreso (CIAP), y por último, José Antonio Mayobre, secretario ejecutivo de la Cepal. 
Un nuevo impulso a la integración: el eje Chile-Colombia y la conformación del grupo andino

Por lo expuesto en el acápite anterior, queda claro que el proceso de integración defendido por el nuevo gobierno demócrata-cristiano superaba el de los cambios puramente económicos. En otras palabras, por medio de esta no solo se buscaba lograr los objetivos económicos y sociales del programa interno, sino que también un desarrollo económico y político a nivel regional, y que América Latina tuviera un papel más importante en el concierto mundial. En este sentido, se promovía un proceso de integración eminentemente político como defendió el gobierno chileno durante la Primera Reunión de Ministros de Relaciones Exteriores de los países de la ALALC en noviembre de $1965^{4}$.

Ahora bien, la reunión de ministros concluyó, como toda reunión de la ALALC, con muchas declaraciones de apoyo al proceso. Pero ese apoyo fue cediendo paso al desinterés, a los recelos y al estancamiento, aumentando la frustración de los países medianos y pequeños que, como Chile, percibían el proceso regional como una salida a sus problemas de desarrollo económico interno.
Por tanto hacia mediados de 1966 se creó un escenario tanto a nivel regional como nacional que impulsó a Frei a tomar acción en pro de acelerar el proceso de integración por medio del establecimiento de un mercado subregional, pero ya no de manera unilateral, sino que en conjunto con su par y amigo colombiano, Carlos Lleras Restrepo. La inoperancia de los instrumentos económicos de integración del Tratado de Montevideo, que habían demostrado ser mecanismos engorrosos para desgravar y facilitar el comercio, estuvieron detrás de esta iniciativa.

Pero el factor político también fue importante en la nueva iniciativa subregional. Y es que el estancamiento de los intercambios y la baja capacidad institucional para destrabar los problemas, traspasaban el ámbito económico para mostrar que la piedra de tope era la diferente manera en que la integración era mirada y pensada para el interés nacional de los distintos países.

Por tanto, la iniciativa subregional estaba sostenida por una fuerte voluntad, en un convencimiento que debía pasarse de las palabras a la acción (Sáez, 1967, p. 7). Un hecho que, sin duda, reflejaba esta intención, era que el intercambio

Los puntos principales defendidos por Chile durante esa reunión, fueron: la creación de instituciones supranacionales que expresaran el interés del conjunto por sobre el nacional; aceleración de los programas de desgravación; el establecimiento de nuevos conceptos de reciprocidad y representación institucionalizada de los empresarios y trabajadores (Valdés, 1965, p. 49). 
comercial entre las economías que iban a pertenecer a la nueva institución era marginal en relación con el total del comercio nacional, llegando solamente al $2 \%$. Por lo que más que una integración para obtener resultados en el presente, en palabras de Frei expresadas en febrero de 1968, era una "integración del futuro" (Wilhelmy, 1976b, pp. 28-29).

De esta manera el gobierno chileno comenzó a realizar una política exterior hacia Latinoamérica en un doble frente; por una parte, no se dejó de apoyar el objetivo de largo plazo y más global de llevar a la ALALC hacia un Mercado Común, mientras que por otra parte se va a propiciar, junto al presidente colombiano, un camino complementario de integración en la Reunión de Bogotá de agosto de 1966. En esta, donde también participaron representantes de Venezuela, Bolivia, Ecuador y Perú, se buscó, a través de una decisión política al más alto nivel, comenzar a pensar una alternativa para que países de similar grado de desarrollo formasen un Mercado Común subregional.

El resultado de la reunión fue la suscripción de la Declaración de Bogotá, documento donde se pusieron las bases del futuro Pacto Andino. En palabras del canciller chileno, este nuevo proceso de integración era "[...] la oportunidad de participar en forma óptima en el mercado común, mediante un acuerdo con un grupo homogéneo de países que permitiera escalas de producción más eficientes de las industrias, orientadas a un mercado más amplio" (Valdés, 1967, p. 40). Estas palabras reflejaban el espíritu de la nueva institución que se proyectaba establecer; es decir, como una acción para impulsar el desarrollo de los países medianos para que en un futuro, de manera más equilibrada, poder integrarse a los países grandes de América Latina.

La consolidación de la integración subregional va a tener un nuevo impulso una vez que se vaya manifestando con mayor profundidad el estancamiento estructural de la integración a través de la ALALC. Un hito clave en ello fue lo que aconteció tras la Conferencia de Punta del Este, donde se reunieron por segunda vez en la historia los mandatarios de todos los países de América ${ }^{5}$, con el objetivo de discutir asuntos económicossociales y profundizar el apoyo político para acelerar el proceso regional. El resultado de la conferencia fue la Declaración de los Presidentes de América, donde junto a extender el condenar al gobierno de Guatemala de Jacobo Arbenz y sus políticas percibidas como "comunistas". 
plazo para la creación del Mercado Común para 1985 -entregándole un nuevo aire y una nueva esperanza a la integración regional-, también se consideró positivo la creación de espacios subregionales al interior de la ALALC (Boletín de la Integración, 1967, pp. 162-163).

Sin embargo, como ya había acontecido antes, a través de los meses se fue pasando del optimismo a la frustración, pues no había voluntad política para destrabar los obstáculos que harían avanzar la integración a través de la ALALC.

Primero fue la conformación del segundo tramo de la lista común que no lograba crearse como producto de que el mayor intercambio entre los miembros de la ALALC era con base en productos agropecuarios, existiendo gran resistencia para que algunos países incluyesen productos delicados para sus economías, como era el petróleo, el trigo y, en el caso de Chile, la carne (Daza, 1967, p. 57). Luego, para la Reunión de Asunción, en 1968, como recordará Valdés, quedó de manifiesto el fracaso de la ALALC debido a que no se logró poner en práctica los pasos acordados en la Conferencia de Punta del Este, esto es, un arancel externo común, un sistema programado de desgravación arancelaria y procedimientos para coordinar las políticas económicas entre los miembros (Wilhelmy, 1976a, pp, 267-268). Por último, lo que terminó sellando la crisis de la ALALC, fue la postergación de estos problemas por medio de la firma del Protocolo de Caracas en diciembre de 1969, que aplazó para el 31 de diciembre de 1974 acordar las nuevas normas para crear la lista común.

En este escenario, la alternativa subregional, de manera opuesta, iba fortaleciéndose institucionalmente y se mostraba como una opción más real y con objetivos más claros, en la medida que no se pretendía volver a repetir los errores que habían estancado a la ALALC. Tras una serie de reuniones por parte de la Comisión Mixta integrada por representantes gubernamentales de los países andinos, se lograron crear las bases del acuerdo subregional que dieron vida, en mayo de 1969, al Acuerdo de Cartagena que constituyó el Grupo Andino.

Entre los objetivos generales de la nueva institución estuvo crear un espacio económico y los instrumentos para un desarrollo industrial conjunto a través de la reducción de los aranceles y otras restricciones no arancelarias; se adoptó un Arancel Externo Común (AEC) hacia terceros países; se coordinaron y armonizaron políticas monetarias, cambiarias y fiscales, y se incluyeron una serie de objetivos específicos de coordinación de políticas económicas y sociales. Es decir, suponía una integración ambiciosa y con una veta política importante que trascendió lo netamente comercial, lo que se desprende de sus fines y objetivos (Rioseco, 1978). 
De lo analizado hasta aquí, se puede observar al gobierno chileno siendo protagonista de una nueva concepción de integración junto a su par colombiano, mostrando una política exterior hacia Latinoamérica de gran convicción y liderazgo. Pero como hemos señalado al comienzo de este trabajo, esta voluntad integracionista no solo fue expresada por el actor gubernamental, pues a nivel de los actores no gubernamentales internos, y sobre todo empresariales, también existió y fue muy importante. De otra manera, ese actuar gubernamental tuvo su correlato interno, y este, en gran medida, respondió, actuó y tomó posición sobre esa política exterior desplegada por el actor gubernamental, así como respecto a los nuevos procesos a nivel continental.

La integración económica para el empresariado: un eje central para el desarrollo privado y un punto de encuentro con el gobierno

Con la llegada al poder en Chile de un partido político de centro progresista, las relaciones entre las principales organizaciones del sector empresarial con el nuevo actor gubernamental se deterioraron enormemente en comparación con la administración anterior. Pese a que los empresarios votaron en su gran mayoría por Frei, como un "mal menor" para que no saliera ganadora la izquierda representada por Salvador Allende, las medidas de reformas estructurales que comenzaron a ser aplicadas por el nuevo gobierno alejó al empresariado de este hasta por lo menos 1967. Como recuerda uno de los principales hombres de empresa del momento, el antagonismo existente no fue porque había ganado un presidente de centro, pues existían altas expectativas pese a no ser el favorito de su sector, sino por las políticas económicas "socializantes" que no privilegiaba a la empresa privada para el desarrollo del país (Heiremans, 2007, p. 288).

Se generó entonces un clima de desconfianza y poca comunicación entre ambos actores, haciendo perder influencia al sector privado en los asuntos públicos, que en el antiguo gobierno si lo tenían. Asimismo, se estaba experimentando una menor influencia en los partidos políticos de centro, como por ejemplo el Partido Radical, al ir inclinándose este hacia tendencias "revolucionarias y socialistas" (Atria, 1973, p. 120). Ello va a prender la alarma en el mundo privado, pues durante los primeros años de la década de 1960 el apoyo que tenían por parte de los partidos políticos, siempre excluyendo a los dos partidos de izquierda -los partidos socialista y comunista-, era amplio, mientras que ahora se reducía solamente a los partidos de derecha. En definitiva, la imagen pública comenzó a estar en juego.

No obstante lo anterior, existió un punto de encuentro entre los empresarios y los sectores políticos, 
es decir los dos partidos de centro y sobre todo el gobierno: nos referimos al apoyo absoluto al proceso de integración económica regional, donde la Sofofa, Asimet y la CPC, no solo continuaron expresando una posición favorable hacia esta durante este período, sino que harán de ella un elemento central de su política presente y futura. Incluso en la máxima asamblea del mundo privado, en la "Convención de la Producción y del Comercio" en abril de 1968, la integración regional fue considerada, en palabras del presidente de la CPC y presidente de la Convención, como un asunto "indispensable para alcanzar el nivel de vida que la región requiere" (El Mercurio, 1968, 30 de marzo).

De esta manera, la política de integración regional del gobierno se convirtió en un punto de encuentro con los empresarios, permitiendo que ellos trabajaran en conjunto con el Ministerio de Relaciones Exteriores para cooperar y verse beneficiados. Fue también un tema donde el sector empresarial pudo ganar influencias sobre determinados centros de decisión a nivel gubernamental, que por afinidades políticas no la tenían. En pocas palabras, a nivel de política interna los empresarios estaban en contra del gobierno y se lo hacían ver en cada oportunidad que podían, pero a nivel externo y sobre todo en la política exterior hacia el proceso de integración, lo apoyaban completamente para que se acelerase la integración económica y se incrementara el comercio exterior chileno (Heiremans, 2007).

Pero, como se señaló, fue principalmente desde 1967 en adelante donde los sectores industriales privados reaparecieron con mayor protagonismo -después de un tiempo de poca aparición pública y poca comunicación con el gobierno-, a fijar sus posiciones respecto al proceso de integración, y respaldar las iniciativas gubernamentales para su mayor dinamismo. Tres fueron las principales instancias donde se hicieron presentes:

a) en un encuentro con el gobierno para discutir los resultados de la Conferencia de Punta del Este; b) en las Jornadas de estudio sobre Gobierno y Empresa frente al Mercado Común; c) y en el nuevo proceso de integración subregional ayudando a su concreción y haciéndose partícipes de sus bases.

Es interesante señalar que en gran medida este nuevo protagonismo va a estar influido por las políticas y acciones del gobierno chileno hacia la integración, así como por los nuevos caminos que tomó el desarrollo de la integración a nivel continental.

La primera de estas instancias se manifestó tras la Reunión de Presidentes Americanos en Punta del Este, donde los mandatarios se comprometieron a crear el Mercado Común. Los resultados de la reunión se convirtieron también en un desafío para las organizaciones empresariales chilenas, así como en un mayor interés por 
volver a ser protagonistas de los nuevos acontecimientos. Por detrás de ese "interés", también existió un cierto grado de conveniencia política en la medida en que se creía que mientras más abiertas estuvieran las fronteras con los países de la región, y al mismo tiempo mayor fuera la interrelación económica con el gobierno, habrían mayores posibilidades de evitar que se aplicasen medidas económicas negativas para la empresa privada (Heiremans, 2007, p. 195).

El primer encuentro que sostuvieron los empresarios con el ejecutivo fue el 27 de abril de 1967, cuando el canciller Valdés invitó al Palacio de La Moneda a los distintos representantes de la economía nacional para informales y analizar tanto la reunión de Punta del Este como el nuevo proceso de integración subregional. $Y$ es que para el gobierno chileno, los acuerdos logrados en Punta del Este tuvieron una connotación especial, pues no solo fueron una ratificación de los esfuerzos que habían venido predicando desde que llegaron al poder, sino que también fueron interpretados como una de las posibles transformaciones económicas más importantes que podrían ocurrir después de la crisis de 1930 o de la Segunda Guerra Mundial. Desde esa mirada se comprende la necesidad del gobierno chileno de exponer, analizar y tomar acciones conjuntas con los sectores económicos más importantes del país (El Mercurio, 1967, 29 de abril).

Por consiguiente, una vez que el canciller expuso los alcances de la Declaración de Presidentes y la relevancia de que en Punta del Este se le haya dado visto bueno a una integración subregional andina, incitará a los empresarios a enfrentar los nuevos desafíos reacomodando las estructuras productivas, cambiando la mentalidad y actitud para competir, y para que adoptaran los nuevos conceptos de crecimiento y la eficiencia. Por lo que terminará expresándoles:

Al Gobierno le corresponde dirigir y orientar el movimiento y crear el marco político y jurídico del nuevo Estado, pero es a toda la comunidad y particularmente a aquellos sectores que tienen una mayor responsabilidad en las decisiones a quienes corresponde tomar también su parte.

Es por ello que a nombre del Cobierno esta tarde invito a ustedes, como lo haré a continuación a otros sectores nacionales, a estudiar estos temas y a proponer las formas en que debemos trabajar prácticamente en conjunto para obtener de la integración y del mercado común los beneficios que Chile puede lograr (Revista Industria, 1967a, p. 10).

Este llamado por parte del canciller tuvo un eco meses más tarde, inspirando una doble iniciativa empresarial: primero las "Jornadas de estudio sobre Gobierno y Empresa frente al Mercado Común Latinoamericano", entre los días 21 y 25 de agosto de 1967, y el segundo, al ser invitados a participar desde muy temprano en la integración subregional andina. 
Respecto al primero de estos acontecimientos, que fue organizado por Asimet, el Instituto Chileno de Administración Racional de Empresas (Icare) y el Instituto Chileno del Acero (ICHA), fue una expresión más de la importancia que volvía a tomar el tema de la integración regional en el mundo empresarial y que sirvió para profundizar los temas abordados en la reunión que tuvieron con el ministro Valdés a finales de abril. Lo que se perseguía en las jornadas era analizar en conjunto los nuevos desafíos que planteaba el proceso regional, así como especificar los cambios necesarios que debían ocurrir a nivel de los empresarios. (El Mercurio, 1967, 27 de julio). En otras palabras, como manifestó el presidente de Asimet, Sergio Markmann, las decisiones que fueron tomadas por los presidentes para acelerar la creación del Mercado Común iban a constituir cambios insospechados que obligaban a estar preparado:

Acordada la iniciación de la desgravación automática para 1970, el país se encuentra abocado a una realidad que no sólo es irreversible e irrevocable, sino también irrenunciable. Ya nadie puede echarse atrás. Por el contrario, la obligación que se nos plantea es empujar el carro hacia adelante con toda nuestra fuerza, porque los acontecimientos se empiezan a medir, ahora, con un calendario regresivo, así como el disparo de los satélites (El Mercurio, 1967, 1 de agosto).
Similar llamado al mundo privado realizó el presidente de Icare, Humberto Díaz, pero enfatizando la nueva actitud y mentalidad que debía adoptar el empresario chileno: "es la hora de la eficiencia. Aquellas empresas que no estén en condiciones de producir a costos y calidad competitivos con empresas de Argentina, Brasil, México, etc., no podrán subsistir. En un régimen de Mercado Común la ineficiencia no podrá ampararse en ningún tipo de proteccionismo" (El Mercurio, 1967, 20 de agosto). Por lo que uno de los objetivos más importantes de las Jornadas apuntaba a comprender que el proceso de integración económica había iniciado un nuevo impulso del cual ellos no podían sustraerse ni mucho menos no prepararse para enfrentarlo de la mejor manera posible. Y lo que estaba en juego, tomando las palabras del presidente de Asimet, era la propia "supervivencia y el porvenir de las industrias" (El Mercurio, 1967, 19 de agosto).

Un hecho destacado del encuentro fue el discurso del presidente Frei ante más de 300 empresarios, ministros de Estado y el presidente de la Corte Suprema. Y era, sin lugar a dudas, el discurso más esperado por todos pues si bien se conocía la posición del gobierno ante el proceso de integración y ya había existido un primer encuentro oficial con el canciller, no había existido aún un pronunciamiento directo y positivo sobre el papel de los empresarios en el proceso de integración y en el 
desarrollo del país por parte de la más alta autoridad del Estado.

Por consiguiente, tras analizar lo que había sido la política de integración de su gobierno, y la fortaleza y compromiso con la que se la ha llevado a cabo desde que llegó al poder, Frei se refirió al papel que tenía la empresa privada en el país y al respaldo absoluto que su administración le confería:

Creo que es esencial, para que el bien común de la nación pueda afianzarse y podamos realizar esta inmensa tarea de desarrollo económico y de desarrollo social, que el sector que hoy ocupa la empresa tenga tranquilidad para trabajar, sepa que mientras sirva al país, el Gobierno reconoce su necesidad e importancia, que necesitamos de su iniciativa, de su inversión, de su confianza y de su esfuerzo y que el Gobierno no cambiará el fundamento de su acción a este respecto (EI Mercurio, 1967, 22 de agosto).

Y tras esas palabras de respaldo, Frei les pedirá que colaboren con sus mayores esfuerzos a la concreción del Mercado Común y a la incorporación de Chile en este:
Por eso yo les pido, como chileno y como presidente de la República, que ayuden en esta tarea del Mercado Común al cual está vinculada la suerte de la empresa chilena y a la cual está vinculada la suerte de los trabajadores chilenos, del Gobierno de Chile y del porvenir de nuestra patria (El Mercurio, 1967, 22 de agosto).

El respaldo del presidente chileno tuvo una gran resonancia a nivel del empresariado, no solo porque convergía con sus intereses y ayudaba a restablecer las buenas relaciones políticas entre ambos actores, sino que también porque para ese entonces, como se señaló al comienzo, la imagen que estaba creándose en la opinión pública y partidos políticos de centro sobre el empresariado no era positiva (El Mercurio, 1967, 23 de agosto).

También las palabras de Frei fueron importantes, porque desde el sector empresarial se había venido desarrollando desde hacía años una demanda para que existiera mayor claridad en los instrumentos de política económica por parte del poder central. Por lo que el discurso del mandatario, junto al que realizó el canciller Valdés en el acto de clausura ${ }^{6}$, fue percibido

\footnotetext{
“El canciller Valdés, quien con su intervención clausuró las Jornadas, reiteró que el gobierno de Frei tenía plena confianza en el papel protagónico que ellos debían cumplir en el proceso de integración, y que por lo mismo pedía confianza en el actuar del poder ejecutivo. Por tanto, al detenerse sobre las inquietudes de los empresarios ante los planteamientos de algunos partidos políticos, expresó que tanto el programa de gobierno, las acciones y discursos de este, como también la Declaración de Presidentes en Punta del Este, habían "demostrado palmariamente de que la empresa privada ha tenido apoyo, respeto y tiene un ancho campo aún no cubierto de iniciativas y acción" (El Mercurio, 1967, 26 de agosto).
} 
como un "espaldarazo" para continuar sintiéndose protagonistas del desarrollo y actuar sin temor para transformarse y competir en el futuro mercado continental (La Nación, 1967, 24 de agosto).

En paralelo a la organización de las Jornadas, que como analizamos tenían a la industria metalúrgica de protagonista y enfatizaba el proceso de integración a través de la ALALC y los resultados de Punta del Este, se estaba desarrollando un segundo frente de participación empresarial en conjunto con el gobierno. Este tenía como actor principal a la Sofofa y buscaba profundizar la integración con los demás empresarios del mundo andino. En lo concreto, esto sucedió cuando representantes de la industria colombiana y chilena se reunieron en Bogotá -con el patrocinio de ambos gobiernos- con ocasión de la inauguración de los vuelos frecuentes entre Santiago y Bogotá a través de Avianca, entre los días 24 y 25 de julio de 1967. Quienes encabezaron la delegación chilena fueron, por parte del gobierno, el vicepresidente de la Corfo, Raúl Saez, y el presidente de la Sofofa, Eugenio Heiremans, realizándose así el primer viaje de empresarios chilenos con patrocinio gubernamental (El Mercurio, 1967, 27 de julio).

Uno de los resultados más destacados del encuentro fue el convenio para aumentar el comercio entre ambos países a través de la industria del azúcar y la industria de la celulosa. El acuerdo estipuló asegurar una compra de azúcar colombiana de alrededor de 20 mil toneladas como mínimo y 70 mil como máximo, mientras que este país se comprometía a comprar un mínimo de 12 mil toneladas de celulosa y un máximo de 20 mil (La Nación, 1967, 28 de julio). Esta negociación, junto con aumentar el comercio y hacer partícipe a los empresarios, también buscaba de manera implícita ser una acción "ejemplificadora" donde los demás países que iban a pertenecer al futuro mercado subregional comprendieran lo que se podía lograr con voluntad y en un mercado más pequeño. Por esto es que los dirigentes empresariales de ambos países realizaron una Declaración Conjunta donde expusieron un respaldo absoluto al proceso de integración andina y a participar activamente en esta y en todas sus etapas. Asimismo estimaron conveniente crear, en cada uno de los países miembros, comisiones mixtas que incluyesen a los sectores públicos y privados para que existiese concordancia con las medidas que se propusieran, y declararon que los sectores empresariales colaborarían lo más posible con la Comisión Mixta (Revista Industria, 1967, p. 21).

La declaración anterior no se quedó en el plano de las palabras, y mientras se desarrollaba en Lima la Cuarta Reunión de la Comisión Mixta, se reunieron en la misma ciudad y por iniciativa de la Sofofa los representantes de las organizaciones empresariales 
andinas. La principal resolución de la reunión fue la creación de un Comité de Empresarios Industriales con carácter permanente que fue reconocido oficialmente como un organismo consultivo y con carácter de obligatoriedad por parte de la Comisión Mixta (Revista Industria, 1967, p. 12). De esta manera, por medio de este organismo existió una institucionalización de la participación del sector privado al estilo del Tratado de Roma, el cual era la principal fuente de inspiración del Acuerdo de Bogotá (Sánchez, 1977, p. 129).

De este modo, el Comité Empresarial del Grupo Andino se convirtió en una organización importante en la configuración del Acuerdo de Cartagena y más adelante en su implementación, en la medida en que colaboró realizando recomendaciones al órgano ejecutivo del Grupo Andino y más tarde a la Junta del Acuerdo.

Por lo examinado en estas tres instancias, donde se muestra a los grupos empresariales chilenos participando del proceso de integración económica y apoyando las acciones del gobierno para dinamizar esos esquemas, se puede comprender cómo el proceso de integración traspasó el solo interés gubernamental. Los grupos empresariales analizados en esta investigación no solo tuvieron una percepción positiva hacia los esquemas de integración sino que también quisieron ser actores protagonistas de esta en pos de su interés sectorial.
Incluso Asimet, quien había sido más distante y receloso hacia el proceso de integración durante el gobierno chileno anterior, ahora tomaba una actitud diferente para lograr insertarse de la mejor manera posible en el Mercado Común.

Por otra parte, no solo primaba en el empresariado la intención de adecuarse para competir en el mercado regional, sino también estaba presente el convencimiento de que entre más integrados económicamente con el resto de los países, habría más garantías de que no se aplicaran medidas internas que fueran en contra de la empresa privada. Por último, debe remarcarse que el mayor interés y participación del sector privado en los temas de integración también fue inducido por las políticas de integración del gobierno chileno, permitiendo que por medio de este tema se alcanzase un alto grado de colaboración entre el sector privado con el poder ejecutivo.

\section{Conclusión}

La manera en que se ha entendido la política exterior en este trabajo, así como el análisis realizado sobre la importancia que tiene considerar en los estudios de política exterior los factores domésticos y sobre todo a los actores no gubernamentales internos, es relevante si se quiere comprender las variables y actores que afectaron el comportamiento de la política exterior de un Estado en un determinado 
proceso de integración, sea este económico o político. Siguiendo a Luis Maira, este enfoque entrega luces sobre las áreas de consenso o conflicto que una determinada política exterior pueda plantear, así como ayuda a discernir los grados de interés nacional o las tendencias a una modificación de criterios respecto a determinados asunto de política exterior (Maira, 1987, p. 413.).

La intención de esta investigación ha tenido el propósito anterior, al analizar cómo la integración latinoamericana durante las décadas de 1960 y 1970 fue un proceso complejo que involucró no solo a los actores gubernamentales sino también a actores no gubernamentales internos -como los grupos empresariales- y cómo se vincularon con las iniciativas de política exterior chilena llevadas adelante por el gobierno. Como hemos analizado, este tipo de actor, en el caso de Chile, participó del proceso regional desde sus propias trincheras comunicacionales y por medio de diversas acciones en la medida en que fueron conscientes que, de su participación en el proceso, dependía si se beneficiarían o no de la integración. Asimismo, muchas veces percibieron que la supervivencia de sus industrias dependía del éxito en la vinculación económica con el resto de los países de la región.

Por tanto, el interés del gobierno de Frei por impulsar y dinamizar la integración regional estuvo en plena sintonía con el pensamiento de los sectores empresariales industriales, permitiendo que fuese un punto de encuentro y apoyo mutuo entre ambos actores. Al mismo tiempo, las iniciativas gubernamentales alentaron a los empresarios para que realizaran acciones que profundizaran la integración regional. Si bien en el caso de Chile siempre había existido un estímulo gubernamental para que los empresarios llevaran a cabo acciones que dinamizaran la integración económica, pareciera haber sido más marcado durante este período en razón del estancamiento que había tenido el proceso durante la primera mitad de la década de 1960.

Se puede destacar, entonces, cómo el gobierno de Frei hizo partícipes como actores protagonistas a los grupos empresariales industriales en la integración de Chile con el resto del continente, entregándoles también un apoyo más amplio en su papel dentro de la sociedad. Igualmente destacable fue la respuesta del sector privado, que se tomó muy seriamente el respaldo gubernamental para que fuesen actores activos de los cambios que iban a ocurrir en la integración regional. Esto los llevó a mantener una posición de plena colaboración con las iniciativas gubernamentales, ayudando al gobierno chileno para que liderara transformaciones que profundizaran la integración económica latinoamericana durante los años 1964 y 1970. 


\section{REFERENCIAS}

Atria, R. Cusack, D. Chellew. P. (1974). Chile: actores y agentes políticos internos del proceso de integración andina, en: Atria, R, (Ed.), Variables políticas de la integración andina, (94-143). Santiago: Instituto de Ciencias Políticas de la Universidad Católica de Chile, Centro Interuniversitario de Desarrollo Andino-Cinda, Ediciones Nueva Universidad.

Bernales, E. (1974). Actores políticos en el proceso de integración andina, en: Atria. R, (Ed), Variables políticas de la integración andina. (76-87). Santiago: Instituto de Ciencias Políticas de la Universidad Católica de Chile, Centro Interuniversitario de Desarrollo Andino, Ediciones Nueva Universidad.

Daza, Pedro. (1964). Tres años de Zona de Libre Comercio. Un esfuerzo para sacarla de la inercia. Revista Ercilla (1.545), 15-19.

Doeser, F. (2011). Domestic politics and foreign policy change in small states: the fall of the Danish 'footnote policy'. Cooperation and Conflict, vol, 46, № 2, 222-241.

El Mercurio. (1964, 11 de diciembre). Chile y la integración latinoamericana.

El Mercurio. (1967, 29 de abril). Acuerdos de presidentes plantean un desafío a la economía chilena.
El Mercurio. (1967, 27 de julio). Jornada sobre el Gobierno y la empresa frente a la ALALC.

El Mercurio. (1967, 19 de agosto). Papel de la empresa en el Mercado Común es vital, dijo S. Markmann.

El Mercurio. (1967, 20 de agosto). Capacidad empresarial será clave del éxito del Mercado Común Latinoamericano.

El Mercurio. (1967, 22 de agosto). Decisión de amparar y estimular.

El Mercurio. (1967, 23 de agosto). En el mercado común. Competir o perecer es el dilema de las empresas.

El Mercurio. 1967. Empresa privada. 23 de agosto de 1967.

El Mercurio. (1967, 26 de agosto). Clausuradas jornadas sobre Mercado Común.

El Mercurio. (1968, 1 de abril). Los empresarios y la integración.

Frei, E. (1964). Mi Programa de Gobierno. Revista Política y Espíritu №, 285, 18-21.

Frei, E. (1965). Nosotros tenemos un destino como Nación; pero lo concebimos en el cuadro de una integración latinoamericana. Revista Política y Espíritu, №, 291, 22-24.

Fermandois, J. (1985). Chile y el Mundo. 1970-1973. La política exterior del Gobierno de la Unidad Popular y el sistema internacional, Santiago: Ediciones Universidad Católica de Chile. 
Fermandois, J. (2005). Mundo y fin de mundo. Chile en la política mundial 1900-2004, Santiago: Ediciones Universidad Católica de Chile.

French-Davis, R. (1973). Políticas económicas en Chile. 1952-1970, Santiago: Ceplan y Ediciones Nueva Universidad.

Fruhling, H. (1983). Proyecto social interno y política exterior: la experiencia chilena desde Frei a Pinochet, en Portales, C., La América Latina en el nuevo orden económico internacional, (223254). México: Fondo de Cultura Económica.

Godoy, H. (1965). Actitudes frente a la integración, en: Romulo. A (Ed), La integración latinoamericana, situación y perspectivas, (141-156). Buenos Aires: Argentina, Instituto para la Integración de América Latina.

Heiremans, E. (2008). Mi visión. Cómo empresarios, trabajadores y políticos cambiamos el país. Santiago: Aguilar.

Hermann, C. (1990). Changing Course: When government choose to redirect foreign policy, International Studies Quaterly, Vol. $34, \mathrm{~N}^{\circ} 1,3-21$.

Hudson, V. (2007). Foreign policy analysis. Classic and contemporary theory, Maryland: Rowman \& Littlefield Publisshers.

Katzenstein, P. (1976). International relations and domestic structures:
Foreign economic policies of advanced industrial states. International Organization, Vol. 30, 1-45.

La Nación. (1967, 24 de agosto). Empresarios confirman su fe en apoyo ofrecido por Gobierno.

Lagos, G. (1972). Chile frente al Grupo Andino y la ALALC: de país líder a país marginal, Revista Mensaje, $\mathrm{N}^{\circ}$ 215, diciembre, 692-695.

Magariños, G. (2005). Integración económica latinoamericana: proceso ALALC/ALADI 1950-2000, Tomo III. Montevideo: BID.

Maira, L. (1987). Los escenarios internacionales y el proceso de formación de las políticas exteriores, en: Wilhelmy. $M$, (Ed), La formación de la política exterior: los países desarrollados y América Latina, Buenos Aires: Grupo Editor Latinoamericano,

Medina, C. (2002). Chile ante la integración latinoamericana. Política exterior, acción diplomática y opinión pública 1960-1976, Tesis doctoral Universidad Complutense de Madrid, Facultad de Geografía e Historia, Departamento de Historia Contemporánea.

Neack, L., Hey, J., Haney. P. (1995). Foreign policy analysis. Continuity and change in its second generation. Englewood Cliffs, N.J.: Prentice Hall.

Putnam, R. (1988). Diplomacy and domestic politics: the logic of 
two-level games. International Organization, Vol. 42, No 3, 428460.

Revista Industria. (1967a). Alcances de los Acuerdos de Punta del Este expuso su canciller a los industriales". №, 4-12, 1-45.

Revista Industria. (1967b). Declaración de Bogotá de industrias privadas. Integración económica de los países del área andina, № , 4-12, 1-45.

Rioseco, A. (1978). El proceso de retiro de Chile del Acuerdo de Cartagena. Revista Estudios Internacionales, №. 32, 1-57.

Sánchez, W. (1977). La organización nacional y regional de la participación del sector empresarial y su incidencia en el desarrollo de la complementación industrial, en: Barros, R. (Ed), La industria en la integración latinoamericana, (127141). Santiago: Ed Universitaria.

Sáez, R. (1967). La Sub-Región Andina: su presente y su futuro, Revista Industria №. 4-12, 1-45.

The Economist. (1965). Bugle call for Latin Unit, №, 6349, 506-507.

Valdés, G. (1967). La política internacional de Chile. Política y Espíritu, №, 302, 39-41.

(1970. Conciencia latinoamericana y realidad internacional. Santiago: Ed del Pacífico.

Van Klaveren, A. (1984). El análisis de la política exterior latinoamericana: perspectivas teóricas, en: Muñoz. H \& Tulchin, J., Entre la autonomía y la subordinación: política exterior de los países latinoamericanos: Buenos Aires Grupo Editor Latinoamericano.

Wilhelmy, M. (1976a). Chilean foreign policy: The Frei government, 19641970. Princeton: N. J., University of Princeton.

(1982a). Democracia, autoritarismo e integración: el caso chileno, en: Wilhelmy, M. (Ed), Sociedad, política e integración en América Latina, (125-147). Santiago, Chile, Cinde.

(1982b) Política, burocracia y diplomacia en Chile, Santiago: Instituto Chileno de Estudios Humanísticos. 